\title{
LICITACIONES PARA EL ABASTECIMIENTO ELÉCTRICO DE CLIENTES REGULADOS EN CHILE DIFICULTADES Y OPORTUNIDADES*
}

\author{
Jorge Moreno \\ Massachusetts Institute of Technology \\ Rodrigo Moreno \\ Imperial College, London \\ Hugh Rudnick \\ Universidad Católica de Chile \\ Sebastian Mocarquer \\ Systep Ingeniería y Diseños
}

Resumen: En 2005 se introdujo en el modelo regulatorio
eléctrico chileno un nuevo esquema de licitaciones de con-
tratos de suministro para las empresas distribuidoras. Se
pretendía instaurar un esquema de mercado de contratos que

Jorge Moreno de la Carrera. Fellow del System Design and Management Program, Massachusetts Institute of Technology (jorge.moreno@sloan. mit.edu).

RodRIGo MoReno. Investigador asociado del Departamento de Ingeniería Eléctrica del Imperial College, Londres, Reino Unido (rmoreno@imperial.ac.uk).

Hugh Rudnick. Profesor Titular de la Pontificia Universidad Católica de Chile, Santiago, Chile (hrudnick@ing.puc.cl).

Sebastian Mocarquer. Director de Systep Ingeniería y Diseños, Santiago, Chile (smocarquer@systep.cl).

* Agradecemos a Óscar Álamos por el procesamiento de la información y a Fondecyt por su apoyo a la investigación.

Estudios Públicos, 125 (verano 2012). 
no sólo incentivara el desarrollo de oferta para asegurar el abastecimiento eléctrico futuro, sino que también diera certeza a los inversionistas. A través de la competencia en las licitaciones, se esperaba lograr precios de largo plazo eficientes. Si bien los conceptos apuntaban a fortalecer el mercado, su aplicación ha restringido el logro de los objetivos originales. Este trabajo resume la aplicación del esquema de licitaciones, sus resultados y limitaciones, identifica lecciones aprendidas y realiza propuestas para perfeccionarlo. El análisis identifica dos problemas fundamentales del mecanismo actual y que tienen que ser abordados y mejorados en futuros procesos: la falta de flexibilidad para enfrentar la incertidumbre futura, y la ausencia de criterios para enfrentar la falta de competencia.

Palabras clave: regulación eléctrica, licitaciones de energía, contratos de suministro eléctrico, tarifas clientes regulados.

Recibido: mayo 2011; aceptado: marzo 2012.

\section{AUCTIONS FOR ELECTRICITY SUPPLY TO REGULATED CUSTOMERS IN CHILE: CHALLENGES AND OPPORTUNITIES}

Abstract: A new auction scheme for supply contracts for the distribution companies was introduced in 2005 in the Chilean electricity regulation. It was intended to establish a contract market scheme that not only would stimulate supply development to ensure future electricity supply, but would also give certainty to investors. Through competitive bidding, it was expected to achieve efficient long-term prices. Although the concepts aimed at strengthening the market, its application has restricted the achievement of the original objectives. This paper summarizes the application of the auction scheme, its results and limitations, identifies lessons learned and makes proposals for improvement. The analysis identifies two fundamental problems of the current mechanism which will have to be addressed and improved in future processes: the lack of flexibility to address future uncertainty and the absence of criteria to address the lack of competition.

Keywords: electricity regulation, energy auctions, electricity supply contracts, regulated costumer rates.

Received: May 2011; accepted: March 2012. 


\section{Introducción}

$\mathbf{E}_{n \text { 1982, el modelo regulatorio chileno fue pionero a nivel }}$ mundial en concebir la existencia de un mercado de generación eléctrica, donde diversos actores privados se disputan el abastecimiento a clientes, dando lugar, en teoría, a condiciones de eficiencia económica en el sector, sin una necesaria participación del Estado en la propiedad de la infraestructura ni en la definición de políticas de desarrollo de largo plazo.

Sin embargo, dicha concepción de mercado sólo se restringió al mercado mayorista de abastecimiento a grandes clientes. Mientras el modelo sirvió de referencia en otros países, donde incluso se extendió la competencia al mercado minorista de pequeños clientes domiciliarios, en Chile se mantuvo la concepción de un mercado minorista regulado, en el cual el Estado, a través de la Comisión Nacional de Energía (CNE), sólo determinaba el precio máximo de los contratos de suministro suscritos entre generadores y empresas generadoras.

Para clientes de menos de 2 MW, la ley eléctrica de 1982 (DFL 1) definió un esquema de cálculo semestral de los denominados precios de nudo, a través de los cuales se buscaba representar la futura evolución de los costos marginales, que eran promediados y traspasados a clientes finales. Los generadores negociaban condiciones de suministro con las distribuidoras, pero los precios de nudo eran calculados semestralmente por la autoridad. Si bien dicho cálculo era ajustado, según fueran los precios promedio del mercado mayorista, en la práctica representaba una acción interpretativa del Estado de las condiciones futuras de mercado en un horizonte máximo de 48 meses.

A partir del año 2004 las empresas distribuidoras eléctricas comenzaron a tener problemas en la renovación de sus contratos de suministro. Esto se produjo por dos motivos: 1) la crisis de suministro del gas argentino, que a partir del mismo año implicó una creciente reducción de las transferencias de gas natural de dicho país que aumentó el costo marginal de energía en el sistema; y 2) los cambios regulatorios que se habían hecho con motivo de la extrema sequía del periodo 19981999. Estos dos efectos implicaron importantes riesgos a las empresas generadoras y a las futuras inversiones en generación de energía.

Desde la perspectiva comercial, los generadores percibían que la renovación de contratos a precios regulados no era la mejor opción y, 
en la medida que dichas obligaciones expiraban, desistieron de adquirir nuevos compromisos.

Consecuentemente, la autoridad decidió realizar un cambio regulatorio, que se concretó en la Ley No 20.018 del 19 de mayo de 2005 (Ley Corta II), la cual remplazó el esquema de precios de nudo por un esquema de licitaciones de suministro de largo plazo de las empresas de distribución eléctrica, obligando a estas últimas a contratarse a través de licitaciones públicas abiertas (según quedó plasmado en el Artículo 131 de la ley eléctrica ${ }^{1}$ ). Se pretendió así resolver el problema instaurando un mercado de ofertas de generación que asegurara el abastecimiento futuro, que no sólo diera certezas a los inversionistas de sus ingresos futuros, sino también, a través de la competencia, lograra los mejores precios posibles (Rudnick \& Mocarquer, 2006).

A pesar de que en un comienzo había señales positivas respecto a la implementación del mecanismo de licitaciones como un instrumento que permitiría dar señales de precios estables y eficientes tanto para generadores como clientes, introduciendo paralelamente mayor competencia al sector mediante la participación de nuevos actores, en la práctica esto no ha sido así. Los resultados obtenidos en un total de diez licitaciones ejecutadas desde el año 2006 sugieren que los precios de largo plazo no representarían adecuadamente el costo de suministro eléctrico de largo plazo. En algunos casos, estos precios alcanzan valores cercanos a los $130 \mathrm{US} \$ \mathrm{MWh}$ sobre un horizonte de largo plazo, sin considerar la componente de pago por potencia. Adicionalmente, la evidencia estudiada demuestra una falta preocupante de competitividad en los procesos y la existencia de varios problemas de diseño.

1 “Artículo $131^{\circ}$. Las concesionarias de servicio público de distribución deberán disponer permanentemente del suministro de energía que, sumado a la capacidad propia de generación, les permita satisfacer el total del consumo proyectado de sus consumidores regulados para, a lo menos, los próximos tres años. Para dichos efectos, con la antelación que fije el reglamento, deberán licitar el suministro necesario para abastecer los consumos de los clientes sometidos a regulación de precios ubicados en su zona de concesión, de modo que el conjunto de los contratos resultantes, más la eventual capacidad de generación propia, garanticen el cumplimiento de la obligación establecida en el inciso anterior. Las licitaciones de suministro serán públicas, abiertas, no discriminatorias y transparentes. Además, la información contenida en las ofertas de los proponentes será de dominio público a través de un medio electrónico. Las concesionarias podrán coordinarse para efectuar una licitación conjunta por la suma de los suministros individuales a contratar". 
Mediante una revisión exhaustiva del proceso de licitaciones, en este trabajo se explica por qué se han obtenido resultados que, desde distintas perspectivas, son cuestionables. Se revisan aspectos como la influencia del nivel de contratación de las empresas en la competitividad de la licitación, el calendario de los procesos y la falta de flexibilidad en el diseño. Adicionalmente se indica que existe un error conceptual al traspasar el diseño del mecanismo a las empresas distribuidoras.

Este artículo está organizado de la siguiente manera: la sección 2 describe aspectos conceptuales del mecanismo de licitaciones, donde además se incluye una revisión de elementos utilizados en otros mercados de interés; la sección 3 explica los elementos a tener en cuenta por los oferentes durante una licitación; la sección 4 presenta los resultados de las licitaciones en el Sistema Interconectado Central (SIC); finalmente, la sección 5 indica algunas lecciones aprendidas y elementos perfectibles.

\section{Aspectos conceptuales del mecanismo de licitaciones: Descripción y comparación internacional}

\subsection{Descripción del mecanismo chileno}

La Ley $\mathrm{N}^{\circ} 20.018$ obliga a los distribuidores a realizar llamados de licitación para el abastecimiento de sus consumos regulados. Las licitaciones de suministro, según esta ley deben ser públicas, abiertas, no discriminatorias y transparentes.

Las licitaciones de electricidad se caracterizan por los siguientes aspectos:

1. Los distribuidores deben tener contratos para garantizar el abastecimiento del $100 \%$ del consumo esperado en los próximos tres años.

2. Los distribuidores deben contratar su energía a través de licitaciones reguladas.

3. Cada distribuidor declara sus requerimientos de contratación definiendo principalmente:

a. el diseño del mecanismo de las licitaciones;

b. la proyección de demanda;

c. el tipo de contrato; 
d. el momento del llamado a licitación;

e. características del bloque licitado (monto de energía a contratar y duración de contrato).

4. Queda a criterio de los distribuidores realizar licitaciones coordinadas con el fin de licitar su demanda conjunta al mismo tiempo.

5. Los distribuidores pueden licitar contratos hasta 15 años a un precio indexado.

6. Antes de la licitación, el regulador establece e informa un precio máximo de energía.

7. Antes de la licitación, el regulador determina el precio de la capacidad.

8. Los ganadores de la licitación deben ser aquellos que presenten las ofertas de mínimo precio.

La normativa exige que el regulador revise y apruebe las bases de licitación propuestas por las empresas distribuidoras. En teoría, para permitir a los inversionistas obtener financiamiento para sus proyectos de generación y disponer del tiempo suficiente para la construcción de nuevas plantas, se concibe que los contratos sean licitados por lo menos tres años antes del inicio del suministro.

Aunque el mecanismo de adjudicación puede cambiar en cada licitación dependiendo del criterio de los distribuidores y el regulador, se ha observado repetidamente la ejecución de un mismo mecanismo que licita simultáneamente distintos contratos. Cada contrato puede permitir ofertas por cantidades menores que el suministro total (sub-bloques de energía). El mecanismo permite además que los generadores realicen ofertas por bloques en varios contratos que en suma sean mayores que su capacidad declarada de producción. No obstante, el licitante debe finalmente adjudicar la mejor combinación de ofertas que cubra el suministro total licitado y respete la capacidad declarada de cada generador.

\subsection{Revisión internacional de procesos de licitaciones de suministro}

A continuación se presenta un resumen de los elementos destacables de otros mecanismos a nivel internacional. Mediante esta descripción se pretende enfatizar aquellos elementos ausentes del esquema chileno y que podrían ser evaluados en futuros procesos en el país. 


\section{Brasil:}

1. Existencia de múltiples tiempos de inicio de suministro diseñados coordinadamente a uno, tres y cinco años a futuro. Esto permite dar una mayor flexibilidad a las carteras tanto de generación como de distribución.

2. Existencia de contratos estándares y agregación de la demanda en bloques de mercado. Esto conlleva varias ventajas, como por ejemplo permitir a las pequeñas empresas de distribución aprovechar las economías de escala.

3. Determinación de peajes de transmisión en el horizonte de contratación previo a la licitación. Esto permite eliminar las primas por riesgo que incluyen los generadores cuando no conocen con certeza sus costos de red.

4. Test de coherencia de costos, lo cual impide que los generadores especulen con las ofertas.

5. Evaluación de las fórmulas de indexación en la adjudicación.

6 . Test de firmeza de las ofertas. Se evalúa si las cantidades ofertadas son confiables ante situaciones donde el sistema está sometido a estrés (e.g. sequía).

\section{Colombia:}

1. El suministro de energía se contrata mediante licitaciones de forwards mientras que el suministro de capacidad se contrata mediante licitaciones de opciones tipo call. La existencia de estos instrumentos aparentemente asegura suministro más eficiente de energía y capacidad.

2. Al igual que en Brasil, se realiza un test de firmeza de las ofertas.

3. Medición ex post del resultado de la licitación. Si las ofertas en la licitación no presentan mínimos estándares que garanticen la ejecución de un proceso competitivo (oferta insuficiente, competencia insuficiente o participación insuficiente), se considera que no existió una licitación normal y se modifican los precios mediante fórmulas regulatorias.

Perú:

1. Existencia de contratos de mediano plazo con restricciones de cobertura. Esto hace más flexibles las carteras de contrato de las distribuidoras. 
2. Precios máximos reservados, lo cual crea un grado de incertidumbre que podría impactar en los niveles de competencia de aquellos procesos con pocos participantes.

\section{Illinois:}

1. Medición ex post del resultado de la licitación. Una comisión determina si los resultados de la licitación fueron competitivos y si, por lo tanto, se pueden aceptar (o no).

Una bibliografía útil referente a estas experiencias y otras similares a nivel mundial se puede encontrar en Moreno et al. (2010).

\section{Modelo conceptual de oferta: Elementos de referencia para los oferentes}

El suministro de energía a clientes regulados mediante la adjudicación de contratos de suministro es parte relevante del negocio eléctrico de los generadores en el Sistema Interconectado Central (SIC), ya que la demanda de dichos clientes representa aproximadamente el 54\% de la demanda total del sistema. En este contexto, la estrategia que los generadores definan es parte principal del negocio de comercialización de energía en el sistema.

Como regla general, las empresas generadoras diseñan sus estrategias de comercialización de energía de acuerdo con sus estructuras productivas y su aversión al riesgo, todo sujeto a las oportunidades que se produzcan en el mercado.

Una estrategia de comercialización consiste en la determinación de los volúmenes de energía que se venderán en el mercado spot y en el mercado de contratos, y para este último, cuánto se venderá a distribuidoras a través de licitaciones y cuánto se venderá a clientes libres o bien a otros generadores a través de contratos libres. En el caso de suministro mediante centrales térmicas se debe agregar la comercialización del recurso energético primario (gas, carbón o diésel).

Al diseñar una estrategia, las empresas generadoras usualmente consideran los siguientes elementos:

1. Costos de las alternativas de generación.

2. Condiciones del mercado eléctrico: En general los precios que son considerados son los costos marginales proyectados para el sistema. Dichos costos marginales están influenciados por las 
características del parque de generación y los precios de los combustibles utilizados por unidades térmicas. Dado el carácter hidrotérmico del Sistema Interconectado Central, una característica importante de los precios es su alta variabilidad en función de la hidrología.

3. Barreras de entrada: El desarrollo de nuevos proyectos eléctricos está condicionado no sólo a la existencia de sitios aptos para su desarrollo y la disponibilidad o acceso a recursos energéticos primarios, sino también a la obtención de permisos ambientales y sectoriales.

4. Coberturas ante variación de precios de combustibles.

Por otra parte, al diseñar su estrategia, las empresas generadoras cuentan con los siguientes elementos:

1. Capacidad de generación: En el caso de centrales hidráulicas corresponde a la generación que se puede lograr con los caudales afluentes según un registro estadístico. En centrales térmicas la capacidad de generación está asociada a la energía generable por la unidad habida consideración de sus necesidades de mantenimiento y su indisponibilidad forzada. En este contexto, es relevante el concepto de energía firme, equivalente a la energía que la central hidroeléctrica es capaz de inyectar al sistema en una condición hidrológica restringida, o aquella que la central térmica puede generar considerando su indisponibilidad.

2. Demanda de energía: Representa las oportunidades que efectivamente pueda tener un generador para establecer contratos de venta de energía con clientes libres o con empresas distribuidoras. Se deben tener en cuenta las ventanas de oportunidad que se visualizan en el mercado, típicamente con el desarrollo de nuevos proyectos industriales, vencimiento de contratos de clientes libres o licitaciones de las empresas distribuidoras.

3. Proyectos de generación y recursos naturales: Corresponde al conjunto de proyectos que la empresa puede impulsar y desarrollar en el mediano plazo. Dentro de esta categoría es posible contabilizar también sitios estratégicos para el desarrollo de proyectos térmicos y derechos de agua para el desarrollo de futuros proyectos hidráulicos. 
4. Alianzas o contratos con otras empresas: Corresponde a la capacidad de la empresa de construir alianzas estratégicas con otros agentes del mercado. Dentro de este ítem es posible contabilizar contratos de compra y venta de energía, contratos de suministros de gas, etc.

Además, es necesario tener presente que, en principio, una empresa generadora tiene la opción de vender toda su energía en el mercado spot y aprovechar eventuales periodos de corto plazo con elevados costos marginales. Sin embargo, ésta es una opción de mayor riesgo, pues los contratos le permiten estabilizar ingresos netos mediante un volumen base que le da seguridad financiera, facilitando el financiamiento de nuevos proyectos y el cumplimiento de obligaciones crediticias.

No es común encontrar en el mercado contratos de corta duración en que un cliente permita que un año le vendan energía a través de un contrato y en otro no. Asimismo, entre grandes clientes se premia habitualmente la relación de largo plazo que agrega valor a la comercialización de energía.

Para un generador lo ideal es, por un lado, maximizar el ingreso neto anual esperado ${ }^{2}$, y por otro, minimizar su volatilidad. En las Figuras $\mathrm{N}^{\text {os. }} 1$ y 2 se representa el coeficiente de variación del ingreso anual $^{3}$, determinado para un generador hidráulico y un generador térmico (carbón) genéricos respectivamente. En este contexto, es posible observar que existe un nivel de contratación en el cual el generador esperaría el mínimo nivel de variación anual de ingreso esperado; si el generador decide establecer un nivel de contratación distinto, necesariamente incurrirá en una mayor volatilidad. El generador podría estar dispuesto a modificar dicho nivel de contratación ideal al aumentar el nivel de precios establecidos en los contratos de suministro; mientras más alto es el precio establecido en dichos contratos, mayor la disposición a establecer un nivel de contratación distinto. Adicionalmente, existen otras medidas de cuantificación de riesgo que permiten analizar la variación del ingreso anual, por ejemplo observando la dispersión

2 Esta sección utiliza el término 'ingreso neto' o simplemente 'ingreso' para referirse a la utilidad operacional o margen comercial del generador.

${ }^{3}$ El coeficiente de variación del ingreso se define como la raíz cuadrada de la varianza del ingreso anual dividida por su valor esperado. Este ingreso se determina en función de la energía comercializada en el mercado spot y energía comercializada mediante contratos. 
FIGURA N ${ }^{\circ}$ 1: $\quad$ ANÁLISIS DE ESTRATEGIA COMERCIAL (DECISIÓN DE NIVEL DE CONTRATACIÓN) DE GENERADOR HIDRÁULICO

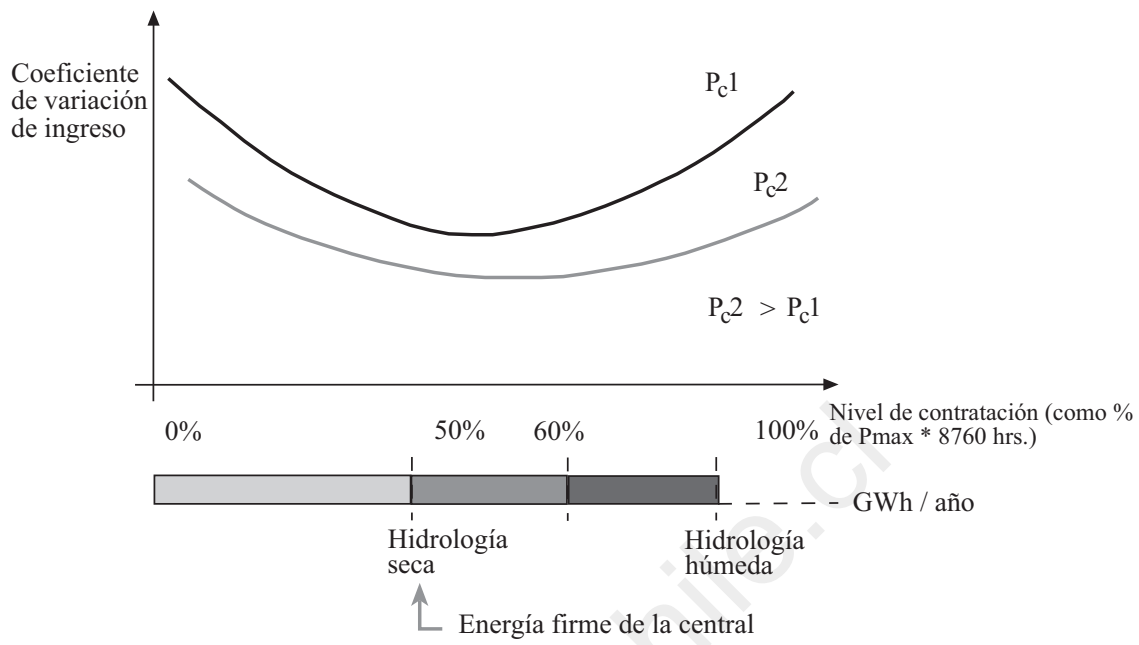

FIGURA No 2: $\quad$ ANÁLISIS DE ESTRATEGIA COMERCIAL (DECISIÓN DE NIVEL DE CONTRATACIÓN) DE GENERADOR TÉRMICO (CARBÓN)

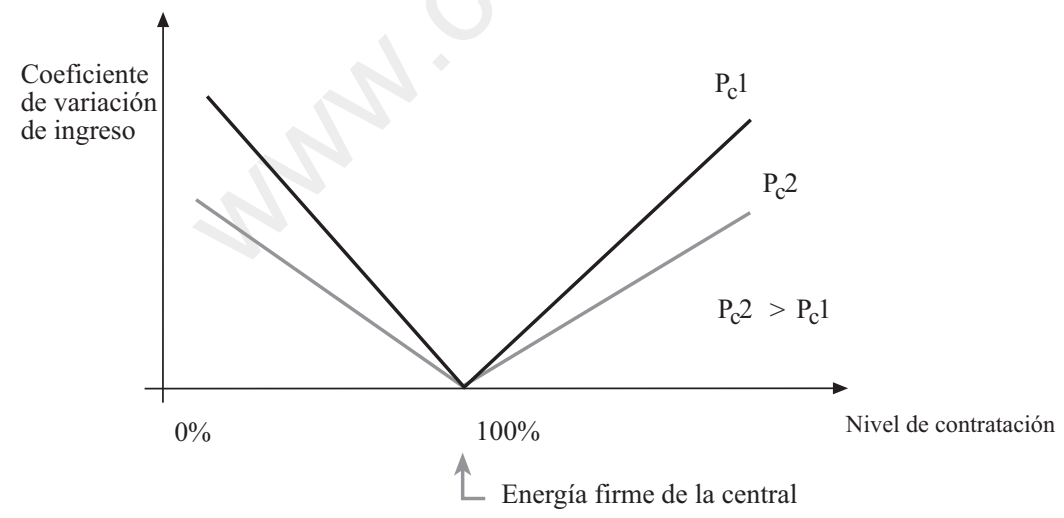

del ingreso mínimo que se podría percibir bajo distintos escenarios de contratación. Estas medidas de cuantificación de riesgo focalizadas en el ingreso mínimo permiten determinar apropiadamente expectativas de servicio de deuda, necesarias para el desarrollo de nuevos proyectos. En este contexto, el objetivo comercial y el riesgo los define la empresa en función de los intereses de sus accionistas y servidores de deuda. 
Lo anterior es importante para entender la dinámica que es posible esperar en licitaciones de suministro eléctrico, sobre todo en el caso chileno, donde la fracción del parque generador hidroeléctrico es importante. Si bien puede existir capacidad instalada suficiente en generación para suministrar la demanda, los generadores estarán dispuestos a ofertar sólo hasta un determinado nivel de contratación; la diferencia entre el nivel de contratación y la capacidad instalada disponible dependerá del tipo de tecnología térmica de generación disponible, la variabilidad del recurso hidráulico y del riesgo de comercialización que las empresas estén dispuestas a asumir ante condiciones de precio determinadas. Por lo tanto, si se considera solamente la oferta de generación disponible, necesariamente los bloques de energía que estén sobre el nivel de contratación óptimo de los generadores tendrán un precio más elevado ${ }^{4}$. Este efecto se torna crítico cuando la contestabilidad del mercado es baja, es decir, existen escasas oportunidades donde agentes puedan participar ofertando la incorporación de nueva capacidad.

En este contexto, durante el periodo 2006-2009 se esperaba que las centrales a carbón aportaran con nueva capacidad instalada al sistema en el largo plazo. La materialización de uno de estos proyectos se caracteriza de la forma indicada en la Tabla $\mathrm{N}^{\circ} 1$.

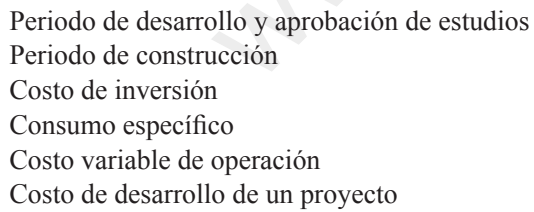

3-5 años

3,5-4,0 años

2.100 a $2.450 \mathrm{US} \$ / \mathrm{kW}$

$\approx 2.490 \mathrm{kcal} / \mathrm{kg}$

43 a 48 US\$/MWh

75 a 90 US\$/MWh

Para el desarrollo de las licitaciones, la posibilidad de contar con nuevos entrantes al mercado parece ser especialmente restrictiva dada la dinámica de desarrollo de los proyectos de generación, cuyos tiempos de construcción difícilmente pueden ser modificados. Por tanto, la posibilidad de atraer nuevos entrantes está aparejada a la restricción temporal de requerir al menos cinco años para el desarrollo de un nue-

${ }^{4}$ Un resultado equivalente se puede ver en investigaciones que utilizan la teoría de portfolio (ver Roubik \& Rudnick, 2009). 
vo proyecto de generación. Es importante destacar que esta restricción también es válida cuando se trata de aumentar la oferta energética por parte de los actores que ya participan en el mercado. Sin embargo, para los actores existentes también está la posibilidad de tener un mayor nivel de contratación, y por tanto considerar temporalmente un mayor riesgo comercial, lo cual sería factible si el precio del bloque marginal contratado compensa el riesgo de dicha mayor contratación.

El desarrollo del sistema de transmisión y las eventuales restricciones que se podrían producir durante el periodo de suministro también deben ser considerados por los oferentes. Restricciones en el sistema de transmisión afectan el costo de comercializar energía en el sistema. En este contexto, futuras congestiones del sistema afectan el despacho y, eventualmente, el nivel de exposición de los agentes en el mercado spot. Además, si el nivel de costo futuro de transmisión — peaje- es desconocido al momento de la licitación, la incertidumbre asociada a este cargo es traspasada al cliente.

\section{Resultados de las licitaciones en el SIC}

Las licitaciones de suministro en el SIC se han desarrollado hasta el 2009 de acuerdo al cronograma expuesto en la Tabla $\mathrm{N}^{\mathrm{o}} 2$.

Básicamente se realizaron tres procesos de licitación de contratos que ya están en ejercicio en el SIC, debiendo efectuarse, en todos los casos, nuevas (sub)licitaciones para contratar el suministro de bloques de energía que no lograron ser adjudicados en la primera instancia (1.233 GWh/año y $9.032 \mathrm{GWh} /$ año en la primera y segunda licitación respectivamente). Sólo el último proceso presentó niveles netos de sobreoferta después de la segunda licitación.

La primera licitación, realizada el año 2006, tuvo un proceso de evaluación y adjudicación de ofertas conjunto. Se licitaron 12.869 GWh/año destinados a abastecer los consumos regulados de Chilectra, Chilquinta, Emel, Saesa y CGE desde el año 2010.

En octubre de 2007, Chilquinta, CGE y Chilectra licitaron 14.869 GWh/año. Se realizó una separación de bloques de acuerdo al año en que se debía comenzar el suministro. Prácticamente el $80 \%$ de los $9.032 \mathrm{GWh} /$ año no adjudicados debían comenzar el suministro en el año 2010. Es importante destacar que en octubre de 2007 se estimaba que parte relevante de la nueva oferta eléctrica en construcción iniciaría 


\begin{tabular}{|c|c|c|c|}
\hline & & & GWh/año \\
\hline \multirow{3}{*}{ Licitaciones 1 y 1.1} & Oct-06 & Energía total licitada & 12.869 \\
\hline & & Energía adjudicada & 11.636 \\
\hline & & Energía no adjudicada & 1.233 \\
\hline \multirow[t]{3}{*}{ Licitación 1.2} & Ene-07 & Energía total licitada & 1.378 \\
\hline & & Energía adjudicada & 1.130 \\
\hline & & Energía no adjudicada & 248 \\
\hline \multirow[t]{3}{*}{ Licitación 2} & Oct-07 & Energía total licitada & 14.732 \\
\hline & & Energía adjudicada & 5.700 \\
\hline & & Energía no adjudicada & 9.032 \\
\hline \multirow[t]{3}{*}{ Licitación 2.1} & Mar-08 & Energía total licitada & 8.800 \\
\hline & & Energía adjudicada & 1.800 \\
\hline & & Energía no adjudicada & 7.000 \\
\hline \multirow[t]{3}{*}{ Licitación 3} & Enero-09 & Energía total licitada & 8.010 \\
\hline & & Energía adjudicada & 7.110 \\
\hline & & Energía no adjudicada & 900 \\
\hline \multirow[t]{3}{*}{ Licitación 3.1} & Jul-09 & Energía total licitada & 850 \\
\hline & & Energía adjudicada & 850 \\
\hline & & Energía no adjudicada & - \\
\hline
\end{tabular}

su operación comercial durante el 2011. Por lo tanto, desde el punto de vista del costo de suministro eléctrico, la industria percibía que el abastecimiento de un contrato a precio fijo durante el año 2010 tenía un riesgo alto, situación que se reflejó en la falta de interés de los distintos actores presentes en el mercado. De la misma forma, no era posible disponer de un nuevo proyecto de generación competitivo en los plazos que se habían dispuesto, hecho que limitó el interés de un nuevo entrante o una nueva central. Esa inteligencia de mercado no fue integrada al proceso ni por el regulador ni por la industria distribuidora.

La Figura $\mathrm{N}^{\mathrm{o}} 3$ muestra los precios medios adjudicados (línea horizontal) en cada una de las licitaciones; junto con ello se presenta la banda entre el precio mínimo y máximo adjudicado, y en círculos, el precio medio indexado a diciembre de 2010. En términos reales, considerando el valor de los indexadores a diciembre de 2010, los precios adjudicados en las licitaciones durante el año 2009 (licitaciones 3 y 3.1) son un $89 \%$ más altos que el promedio de los contratos adjudicados 
FIGURA N ${ }^{\circ}$ 3: $\quad$ PRECIOS, SIN INDEXAR, ADJUDICADOS EN CADA LICITACIÓN

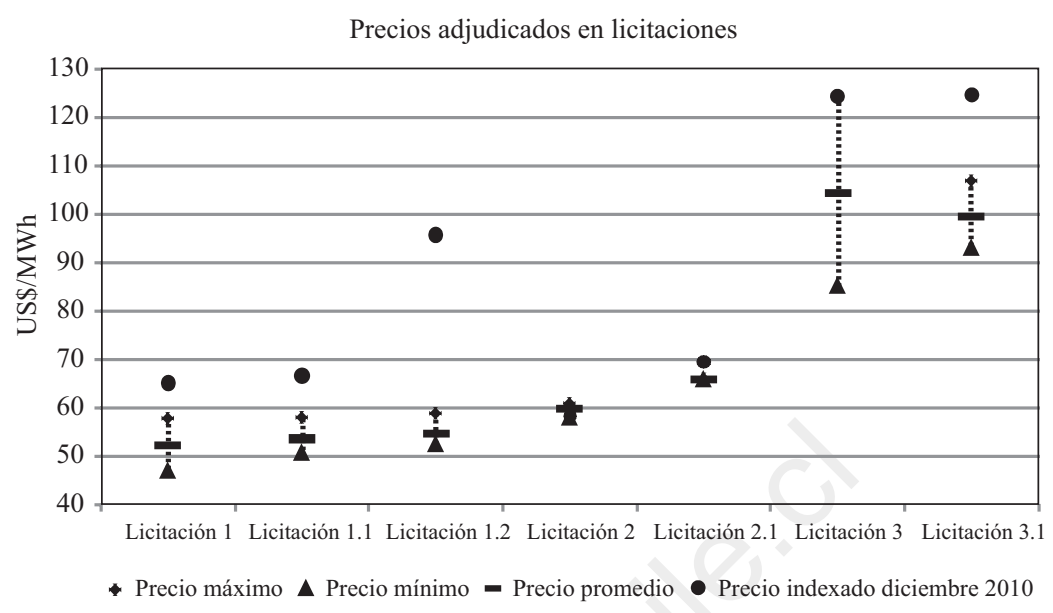

previamente. En este contexto, es importante entender de qué forma, en promedio, los generadores indexaron los precios de la energía en cada etapa (Tablas Nos. 3 y 4). A continuación se exponen los aspectos más relevantes de cada proceso.

Licitación 1: La energía fue indexada al CPI, carbón, GNL y diésel, en proporciones de $54 \%, 27,5 \%, 8,8 \%$ y 9,7\% respectivamente. La componente diésel se debe a que Colbún indexó, en contratos con Saesa y CGE, el $25 \%$ de $2.782 \mathrm{GWh} /$ año a este combustible. El precio promedio adjudicado fue de 52,2 US\$/MWh; el cual, indexado a diciembre de 2010, equivale a 65,1 US\$/MWh.

Licitación 1.1: La energía fue indexada al CPI, carbón y GNL, en proporciones de $64,3 \%, 27,7 \%$ y $8 \%$ respectivamente. El precio promedio adjudicado fue de 53,6 US\$/MWh; el cual, indexado a diciembre de 2010, equivale a 66,6 US\$/MWh.

Licitación 1.2: Producto de las ofertas realizadas por Gener a Emel, la energía fue indexada en su totalidad al carbón. El precio promedio adjudicado fue de 54,5 US\$/MWh, el cual, indexado a diciembre de 2010, equivale a 95,7 US\$/MWh. Estos contratos, tal como se revisará más adelante, son particularmente importantes de destacar, pues el generador escogió una estrategia de mayor riesgo al indexar la totalidad 
TABLA N ${ }^{\circ}$ :

INDEXACIÓN PROMEDIO DE LOS CONTRATOS ADJUDICADOS EN CADA LICITACIÓN

\begin{tabular}{lccccc}
\hline Licitación & $\begin{array}{c}\text { Año } \\
\text { licitación }\end{array}$ & $\begin{array}{c}\text { Energía } \\
\text { licitada } \\
\text { [GWh/año] }\end{array}$ & $\begin{array}{c}\text { Precio } \\
\text { medio } \\
\text { adjudicado } \\
\text { [US\$/MWh] }\end{array}$ & $\begin{array}{c}\text { Precio medio } \\
\text { indexado } \\
\text { a dic-10 } \\
{[\text { USWWh] }}\end{array}$ & $\begin{array}{c}\text { Año de } \\
\text { inicio de } \\
\text { suministro }\end{array}$ \\
\hline Licitación 1 & 2006 & 7.136 & 52,2 & 65,1 & 2010 \\
Licitación 1.1 & 2006 & 4.500 & 53,6 & 66,6 & 2010 \\
Licitación 1.2 & 2007 & 1.130 & 54,5 & 95,7 & 2010 \\
Licitación 2 & 2007 & 5.700 & 59,8 & 58,3 & 2011 \\
Licitación 2.1 & 2008 & 1.800 & 65,8 & 69,5 & 2011 \\
Licitación 3 & 2009 & 7.110 & 104,3 & 124,2 & 2010 \\
Licitación 3.1 & 2009 & 850 & 99,5 & 124,5 & 2010 \\
\hline
\end{tabular}

TABLA N ${ }^{\circ}$ :

INDEXACIÓN PROMEDIO DE LOS CONTRATOS ADJUDICADOS EN CADA LICITACIÓN

\begin{tabular}{|c|c|c|c|c|c|c|c|c|}
\hline \multirow[t]{2}{*}{ Licitación } & \multicolumn{2}{|c|}{ CPI } & \multicolumn{2}{|c|}{ Carbón } & \multicolumn{2}{|c|}{ GNL } & \multicolumn{2}{|c|}{ Diésel } \\
\hline & $\begin{array}{l}\text { Valor } \\
\text { base }\end{array}$ & $\begin{array}{c}\% \\
\text { index. } \\
\text { prom. }\end{array}$ & $\begin{array}{l}\text { Valor } \\
\text { base }\end{array}$ & $\begin{array}{c}\% \\
\text { index. } \\
\text { prom. }\end{array}$ & $\begin{array}{l}\text { Valor } \\
\text { base }\end{array}$ & $\begin{array}{c}\text { \% } \\
\text { prom. } \\
\text { index. }\end{array}$ & $\begin{array}{l}\text { Valor } \\
\text { base }\end{array}$ & $\begin{array}{c}\% \\
\text { index. } \\
\text { prom. }\end{array}$ \\
\hline Licitación 1 & 196,80 & $54,0 \%$ & 67,92 & $27,5 \%$ & 8,68 & $8,8 \%$ & 526,61 & $9,7 \%$ \\
\hline Licitación 1.1 & 198,30 & $64,3 \%$ & 67,75 & $27,7 \%$ & 7,54 & $8,0 \%$ & 523,80 & $0,0 \%$ \\
\hline Licitación 1.2 & 196,80 & $0,0 \%$ & 67,92 & $100,0 \%$ & 8,68 & $0,0 \%$ & 526,61 & $0,0 \%$ \\
\hline Licitación 2 & 206,69 & $83,2 \%$ & 97,75 & $0,0 \%$ & 7,31 & $16,8 \%$ & 573,36 & $0,0 \%$ \\
\hline Licitación 2.1 & 206,69 & $100,0 \%$ & 97,75 & $0,0 \%$ & 7,31 & $0,0 \%$ & 573,36 & $0,0 \%$ \\
\hline Licitación 3 & 216,66 & $100,0 \%$ & 192,99 & $0,0 \%$ & 9,53 & $0,0 \%$ & 856,04 & $0,0 \%$ \\
\hline Licitación 3.1 & 216,66 & $100,0 \%$ & 192,99 & $0,0 \%$ & 9,53 & $0,0 \%$ & 856,04 & $0,0 \%$ \\
\hline
\end{tabular}

del contrato a dicho combustible ${ }^{5}$. Este hecho no sería una práctica habitual para un desarrollador de una planta de estas características. Durante el año 2008, producto del alza generalizada en los precios de los combustibles, la indexación de este contrato alcanzó precios superiores

${ }^{5}$ La estructura de costos de un proyecto térmico está dada principalmente por costos combustibles (carbón) y pagos asociados al capital invertido, estos últimos generalmente están indexados al CPI y a una tasa de referencia. Al indexar el contrato completamente al precio del carbón, la porción del ingreso sujeta al pago del capital queda asociada a la volatilidad del mercado del carbón. 
a $200 \mathrm{US} \$ \mathrm{MWh}^{6}$, oportunidad en que el precio promedio indexado de todos los contratos licitados era 91,1 US\$/MWh (Figura $\mathrm{N}^{\circ}$ 4).

Tras el primer proceso de licitación, sólo Endesa, Colbún, Gener y Guacolda adjudicaron contratos; no se logró incorporar a un nuevo actor al mercado, y sólo Guacolda comprometió nuevas inversiones explícitamente en los contratos ${ }^{7}$.

Licitación 2: Los contratos fueron indexados al CPI y GNL, en proporciones de $83,2 \%$ y $16,8 \%$ respectivamente. El precio promedio adjudicado fue de 59,8 US\$/MWh, el cual, indexado a diciembre de 2010, equivale a 58,3 US\$/MWh. Sólo se recibieron ofertas de Colbún y Endesa, lográndose contratar $5.700 \mathrm{GWh} /$ año correspondientes a aquellos bloques de energía cuyo periodo de suministro comenzaba a partir del año 2011, por tanto, quedó una demanda de $9.032 \mathrm{GWh} /$ año no contratada, cuyo suministro debía comenzar el año 2010.

A esta fecha los generadores ya habían adjudicado el suministro de $18.466 \mathrm{GWh} /$ año en procesos de licitación. Este bloque de energía, sumado a la energía previamente comprometida en contratos vigentes (con clientes libres y regulados), con término posterior al 2010, probablemente había copado el nivel de contratación a bajo riesgo (relacionado con la energía firme que el generador es capaz de producir a precios competitivos). En este contexto, es importante tener en consideración que el precio máximo que los generadores podían ofertar en esta etapa estaba limitado por lo dispuesto en el Artículo $2^{\circ}$ del D.S. $147^{8}$, de manera que el precio de las ofertas no podía ser superior a 61,682 US\$/ MWh, precio que, dada la estrechez de oferta esperada para el año 2010 y el diseño de la licitación, no era suficiente para compensar el riesgo de un eventual alto costo de suministro.

${ }^{6}$ De acuerdo a la programación semanal del CDEC-SIC del 15 de noviembre de 2008, el costo variable de la unidad a carbón más cara del sistema (Bocamina) era 64,8 US\$/MWh. Para comparar este valor con el precio del contrato, debe agregarse la amortización de la inversión de la central.

${ }^{7}$ De acuerdo a la Sección 7.3 de las bases, y al Formulario Anexo $\mathrm{N}^{\circ} 5$, los oferentes deben informar si el abastecimiento se realizará mediante un nuevo proyecto de generación. El proyecto térmico a carbón, Guacolda 3, de $135 \mathrm{MW}$, fue comprometido en la licitación para abastecer $900 \mathrm{GWh} /$ año a Chilectra.

${ }^{8}$ Decreto de Precio de Nudo, Artículo segundo: “[...] En virtud de lo establecido en el artículo $135^{\circ}$ de la LGSE, en cada licitación para abastecer consumos regulados, el valor máximo de las ofertas será el equivalente al límite superior de la Banda de Precios de Mercado (BPM) establecida en el artículo $168^{\circ}$ de la LGSE, aumentado en un 20\%". 
FIGURA N ${ }^{\circ}$ 4: $\quad$ PRECIOS DE LOS CONTRATOS - INDEXADOS-ADJUDICADOS POR CADA GENERADOR

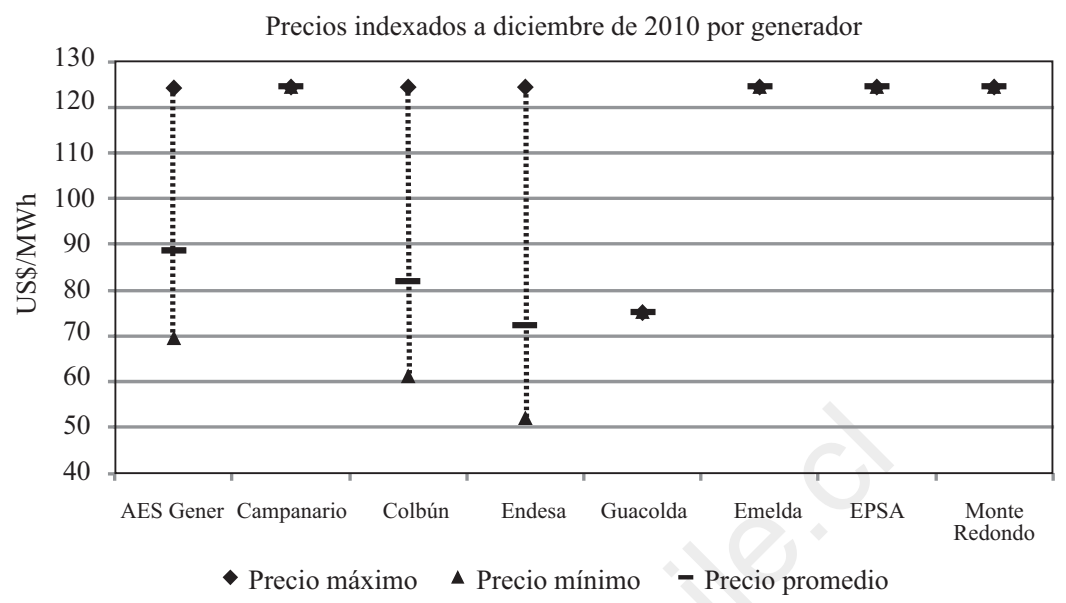

Licitación 2.1: Se licitaron $8.800 \mathrm{GWh} /$ año correspondientes al suministro de Chilquinta, CGE y Chilectra no adjudicados en la licitación anterior. El bloque de Chilectra, cuyo inicio de suministro era el año 2011, fue adjudicado a un único oferente: Gener. El contrato fue indexado al CPI. El precio adjudicado fue de 65,8 US\$/MWh, el cual indexado a diciembre de 2010 equivale a 69,5 US\$/MWh.

La escasa posibilidad de suministrar un bloque de $7.000 \mathrm{GWh}$ el año 2010 con costos competitivos dio lugar a que las empresas generadoras no estuvieran dispuestas a asumir el riesgo de firmar contratos de largo plazo a precio fijo. Desde la perspectiva comercial, existía una alta posibilidad de incurrir en una pérdida durante los primeros años, no creando valor para las compañías durante los primeros años. Asimismo, las bases de los contratos licitados hasta marzo de 2008 no permitían traspasar temporalmente el riesgo de variaciones en el costo del suministro eléctrico al cliente. Producto de ello, las empresas distribuidoras y la CNE optaron por modificar las bases e introducir como indexador del precio del contrato las variaciones que experimentara el costo marginal durante los dos primeros años. A partir del año 2012, el precio de los contratos estaría indexado al precio de los combustibles y CPI, según sea la opción de cada oferente. 
Licitación 3: Por primera vez se presentaron nuevos actores al proceso de licitación, los que se adjudicaron entre un $10 \%$ y $15 \%$ de la energía licitada (Campanario Generación, propietaria de 180 MW de generación dual, y Monte Redondo, parque eólico de 38 MW). No se puede argumentar que estos dos nuevos actores entraron directamente con motivo de la licitación, pues la materialización de ambos proyectos había sido decidida con anterioridad. Se licitaron $8.010 \mathrm{GWh} /$ año correspondientes al suministro de CGE, Saesa y Chilquinta. El precio promedio adjudicado fue de 104,3 US\$/MWh, indexado en un $100 \%$ al CPI a partir del año 2012. El precio medio indexado a diciembre de 2010 es de 124,2 US\$/MWh. A pesar del alto precio de cierre, quedaron sin adjudicar $900 \mathrm{GWh} /$ año para el suministro de CGE.

Licitación 3.1: Realizada en julio de 2009. Las compañías Eólica Monte Redondo, Epsa y Empresa Eléctrica Diego de Almagro (Emelda) se adjudicaron $53 \%$ de la energía licitada, dejando fuera de competencia a un actor relevante del mercado: Guacolda. El 47\% restante se lo adjudicó Endesa. El precio promedio adjudicado fue de 99,5 US\$/MWh, indexado en $100 \%$ al CPI a partir del año 2012. El precio medio indexado a diciembre de 2010 es de 124,5 US\$/MWh. En este caso particular, es importante destacar la estrategia de Emelda, generador diésel de 76 MW que se adjudicó $200 \mathrm{GWh} /$ año a un precio promedio de 101,7 US\$/MWh. En este sentido, dados los costos de generación del diésel, no se espera que dicha central aporte nueva energía al sistema en una situación normal de suministro eléctrico, por lo que necesariamente deberá realizar compras en el mercado spot, actuando sólo como comercializador de energía.

Un aspecto a destacar es el nivel de firmeza de algunos de los contratos pactados en estos procesos de licitaciones. Por ejemplo, la energía asociada a los contratos de Monte Redondo supone un factor de planta por sobre valores creíbles de disponibilidad para la tecnología en cuestión, en torno al $65 \%$.

La Tabla $N^{0} 5$ y la Figura $N^{o} 4$ presentan los resultados por generador. Se expone la energía adjudicada por cada uno de ellos; el precio promedio, mínimo y máximo de los contratos licitados, y la estructura promedio de indexación de sus contratos. En términos generales se observa que Endesa, Gener, Guacolda y Colbún tienen los menores precios promedio adjudicados, indexando a variables que reflejan el riesgo de su matriz de generación (por ejemplo $70 \%$ CPI y $30 \%$ a la matriz de 
TABLA N ${ }^{\circ}$ 5: $\quad$ INDEXACIÓN PROMEDIO DE LOS CONTRATOS UTILIZADOS POR CADA GENERADOR

\begin{tabular}{|c|c|c|c|c|c|c|c|c|}
\hline Generador & $\begin{array}{c}\text { Energía } \\
\text { licitada } \\
\text { [GWh/ } \\
\text { año] }\end{array}$ & $\begin{array}{c}\text { Precio } \\
\text { máximo } \\
\text { index. } \\
\text { dic-10 } \\
\text { [US\$/ } \\
\text { MWh] }\end{array}$ & $\begin{array}{c}\text { Precio } \\
\text { mínimo } \\
\text { index. } \\
\text { dic-10 } \\
\text { [US\$/ } \\
\text { MWh] }\end{array}$ & $\begin{array}{l}\text { Precio } \\
\text { medio } \\
\text { index. } \\
\text { dic-10 } \\
\text { [US\$/ } \\
\text { MWh] }\end{array}$ & $\begin{array}{c}\text { CPI } \\
\% \\
\text { index. } \\
\text { prom. }\end{array}$ & $\begin{array}{c}\text { Carbón } \\
\% \\
\text { index. } \\
\text { prom. }\end{array}$ & $\begin{array}{c}\text { GNL } \\
\% \\
\text { index. } \\
\text { prom. }\end{array}$ & $\begin{array}{c}\text { Diésel } \\
\% \\
\text { index. } \\
\text { prom. }\end{array}$ \\
\hline AES Gener & 5.419 & 124,3 & 69,5 & 88,6 & 67,9 & 32,1 & 0,0 & 0,0 \\
\hline Campanario & 1.750 & 124,5 & 124,5 & 124,5 & 100,0 & 0,0 & 0,0 & 0,0 \\
\hline Colbún & 6.782 & 124,5 & 61,2 & 81,9 & 71,3 & 18,5 & 0,0 & 10,3 \\
\hline Endesa & 12.825 & 124,5 & 52,0 & 72,4 & 77,2 & 7,7 & 15,2 & 0,0 \\
\hline Guacolda & 900 & 75,2 & 75,2 & 75,2 & 60,0 & 40,0 & 0,0 & 0,0 \\
\hline Emelda & 200 & 124,5 & 124,5 & 124,5 & 100,0 & 0,0 & 0,0 & 0,0 \\
\hline EPSA & 75 & 124,5 & 124,5 & 124,5 & 100,0 & 0,0 & 0,0 & 0,0 \\
\hline Monte Redondo & 275 & 124,5 & 124,5 & 124,5 & 100,0 & 0,0 & 0,0 & 0,0 \\
\hline
\end{tabular}

combustibles). Los contratos de los nuevos actores: Campanario, Emelda, Epsa y Monte Redondo, fueron adjudicados a precios cercanos a los 100 US\$/MWh, indexados a partir del año 2012 en su totalidad al CPI. Dado que Emelda y Campanario son generadores térmicos (diésel), la indexación de contratos sólo al CPI parece ser un acto agresivo desde el punto de vista del riesgo del costo de suministrar dichos contratos.

La Figura $\mathrm{N}^{\circ} 5$ presenta la evolución histórica de los precios de los contratos licitados. Se expone el precio mínimo, medio y máximo mensual. En diciembre de 2010, el precio medio fue de 82,1 US\$/ MWh. Es posible observar cómo durante todo el periodo ha existido una amplia diferencia entre el precio promedio y el máximo adjudicado. En este contexto, aislando el efecto de los precios adjudicados en la tercera licitación, en donde de acuerdo a lo ilustrado en la Figura $\mathrm{N}^{\mathrm{o}} 3$ se obtuvieron los precios más altos, es importante abordar las causas de las diferencias, pues aparentemente al momento de adjudicar los contratos éstas no eran evidentes.

Para ilustrar la importancia de la evaluación de las fórmulas de indexación en el proceso, se estudiaron las ofertas realizadas en la licitación 1.2 en febrero de 2007 para el bloque Emel-Sur de $770 \mathrm{GWh} /$ año. En aquella oportunidad, Emel recibió dos ofertas: 
FIGURA N ${ }^{\circ}$ 5: $\quad$ EVOLUCIÓN HISTÓRICA DE LOS PRECIOS —INDEXADOSADJUDICADOS EN LAS LICITACIONES

Análisis de precios adjudicados en las licitaciones

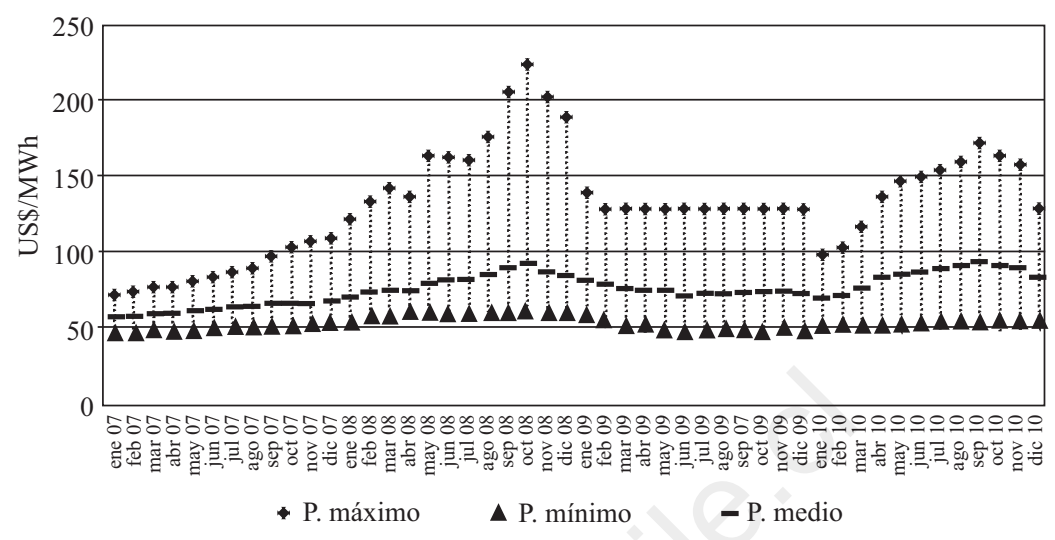

- Gener: precio 52,49 US\$/MWh, indexado 100\% al carbón (oferta adjudicada).

- Colbún: precio 57,64 US\$/MWh, indexado 55\% al CPI y $45 \%$ al carbón (oferta no adjudicada).

Tras comparar los precios ofertados, es posible concluir que existió una diferencia de $10 \%$ entre el precio de Colbún y el de Gener. Sin embargo, si dichos precios se indexan a la fecha de adjudicación, esta diferencia disminuye sólo a $1 \%{ }^{9}$. En este contexto, vale la pena cuestionar qué contrato podría presentar menor volatilidad; un contrato que tiene una mayor componente indexada al CPI pareciera ser más favorable en este sentido. Los resultados de una evaluación ex post de ambos contratos se presentan en la Figura $\mathrm{N}^{\circ}$ 6. Prácticamente durante todo el periodo de evaluación el contrato no adjudicado a Colbún habría resultado más favorable para los clientes.

De la misma manera, es posible argumentar que un generador con una matriz predominantemente térmica no debiera estar dispuesto a indexar un contrato en una componente importante al CPI sin un premio por riesgo implícitamente incorporado en el precio. De todas formas, en

${ }^{9}$ El precio de los contratos indexados de Gener y Colbún, a enero de 2007, es 62,96 US\$/MWh y 63,62 US\$/MWh respectivamente. En este sentido, es importante destacar que la evaluación de las ofertas se realiza sin indexar (o actualizar) los precios. 
FIGURA N ${ }^{\circ}$ 6: $\quad$ COMPARACIÓN EX POST DE EVOLUCIÓN OFERTAS BLOQUE EMEL-SUR. GENER (ADJUDICADO)-COLBÚN (NO ADJUDICADO)

Análisis ofertas Emel 2a licitación del 2006

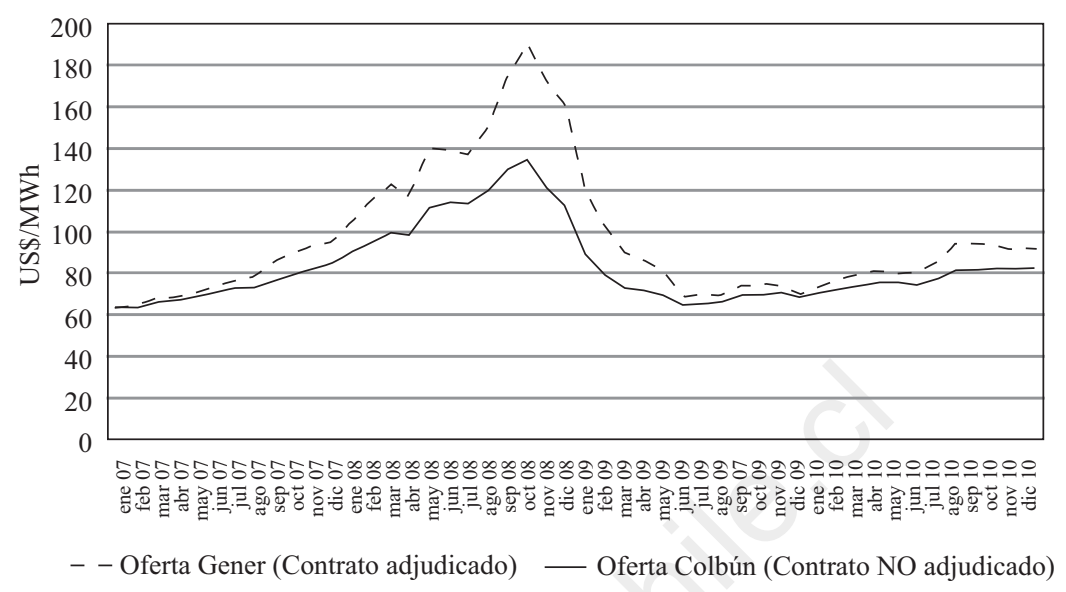

términos generales la estructura de costos de operación de un proyecto térmico está dada principalmente por costos de combustibles y pagos asociados al capital invertido (asociado al servicio de la deuda), estos últimos generalmente están indexados a CPI.

Con el caso expuesto queda de manifiesto el hecho que no definir un criterio para evaluar las indexaciones de los precios de los contratos al momento de la adjudicación de las ofertas puede introducir distorsiones que favorezcan una toma de decisiones errada, afectando la eficiencia del mecanismo y así las tarifas finales. Más aún, se crean espacios para que un generador, poseedor de un conjunto de contratos, para una licitación pueda optar por una estrategia más agresiva desde el punto de vista de precios, pero más riesgosa para el cliente. Incluso puede darse el caso que, al momento de realizar la licitación, la coyuntura internacional de los precios de los combustibles introduzca distorsiones en la evaluación de las ofertas. En el proceso de definición de la Ley Corta II se consideró la alternativa de establecer una indexación única para todas las ofertas, pero se privilegió el dejar que cada oferente decidiera esto en función de sus riesgos. Por ejemplo, que un generador a carbón buscara protegerse de la evolución del precio de este combustible y por ende indexara su oferta a ello. 
La Tabla No 6 y la Figura $\mathrm{N}^{\mathrm{o}} 7$ resumen los resultados obtenidos por empresa distribuidora. Chilectra es la compañía que obtuvo precios más económicos, con precios indexados en $79 \%$ al CPI, 10\% al carbón y $11 \%$ al GNL. Por su parte Emel, si bien parece tener poca diferencia entre el precio mínimo y máximo adjudicado, tiene sus contratos indexados en mayor proporción a los precios de los combustibles, en particular, un $63 \%$ al carbón y un $7 \%$ al GNL. Chilquinta y CGE tienen una alta proporción de sus contratos indexados al CPI, pero esto es sólo a partir del año 2012, previo a ello, el costo de la energía está indexado a las variaciones del costo marginal.

\section{TABLA N ${ }^{\circ}$ 6: $\quad$ EVALUACIÓN DE PRECIOS ADJUDICADOS POR DISTRIBUIDORA}

\begin{tabular}{|c|c|c|c|c|c|c|c|c|c|c|c|}
\hline EEDD & $\begin{array}{c}\mathrm{GWh} / \\
\text { año }\end{array}$ & $\begin{array}{l}\text { Año de } \\
\text { inicio } \\
\text { de sumi- } \\
\text { nistro }\end{array}$ & $\begin{array}{c}\text { Precio } \\
\text { máximo } \\
\text { index. } \\
\text { dic-10 } \\
\text { [US\$/ } \\
\text { MWh] }\end{array}$ & $\begin{array}{c}\text { Precio } \\
\text { mínimo } \\
\text { index. } \\
\text { dic-10 } \\
\text { US\$/ } \\
\text { MWh] }\end{array}$ & $\begin{array}{c}\text { Precio } \\
\text { medio } \\
\text { index. } \\
\text { dic-10 } \\
\text { US\$/ } \\
\text { MWh] }\end{array}$ & CPI & Carbón & GNL & Diésel & $\begin{array}{c}\text { Energía } \\
\text { index. } \\
\text { a CMg } \\
{[\mathrm{GWh}]}\end{array}$ & $\begin{array}{c}\text { Energìa } \\
\text { index. } \\
\text { a CMg } \\
{[\%]}\end{array}$ \\
\hline Chilectra & 12.000 & $2010 / 2011$ & 80,84 & 55,84 & 63,10 & $79 \%$ & $10 \%$ & $11 \%$ & $0 \%$ & - & $0 \%$ \\
\hline Chilquinta & 2.567 & 2010 & 124,30 & 55,44 & 103,95 & $90 \%$ & $7 \%$ & $4 \%$ & $0 \%$ & 1.760 & $69 \%$ \\
\hline EMEL & 2.007 & 2010 & 103,40 & 61,41 & 80,71 & $31 \%$ & $63 \%$ & $7 \%$ & $0 \%$ & - & $0 \%$ \\
\hline CGE & 7.220 & 2010 & 124,51 & 56,77 & 109,36 & $88 \%$ & $7 \%$ & $2 \%$ & $2 \%$ & 5.350 & $74 \%$ \\
\hline Saesa & 4.432 & 2010 & 124,51 & 51,99 & 77,43 & $57 \%$ & $26 \%$ & $5 \%$ & $12 \%$ & 850 & $19 \%$ \\
\hline
\end{tabular}

FIGURA N N $^{\circ}$ EVALUACIÓN DE PRECIOS ADJUDICADOS POR DISTRIBUIDORA

Precios de los contratos por empresa distribuidora (Indexados a diciembre de 2010)

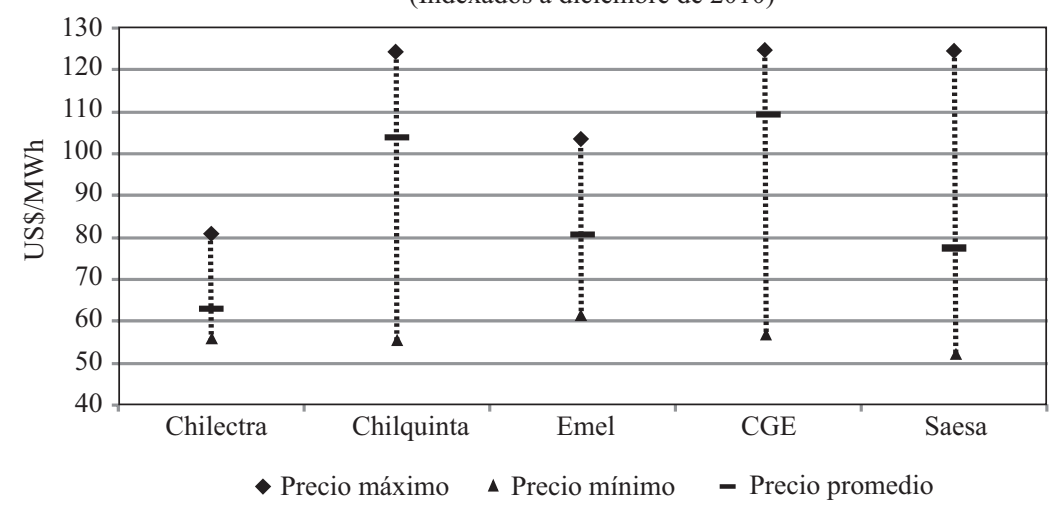


CGE realizó estimaciones ambiciosas de crecimiento de la demanda ${ }^{10}$ que podrían justificar, en parte, los mayores precios que obtuvo. Básicamente la empresa distribuidora está comprando una opción para absorber futuros crecimientos en la demanda, pero no incorpora el eventual perjuicio al consumidor de dicha opción. Tal como se presentó en las Figuras $\mathrm{N}^{\text {os. }} 1$ y 2 , un generador anticipando una venta menor que la contratada puede reducir su riesgo ofreciendo mayores precios. Asimismo, asumiendo que no hay adiciones de capacidad en el corto plazo y el generador ya tiene un nivel de contratación cercano al óptimo comercial, el precio a ofertar por el bloque marginal debiera ser más alto.

En términos generales, el precio de los contratos de los clientes regulados quedó indexado de acuerdo a lo que se ilustra en la Tabla $\mathrm{N}^{\circ} 7$. En los años 2010 y 2011 el costo de la energía quedó indexado en un $28 \%$ al costo marginal. A partir del año 2012, el precio de la energía estará indexado en un $75 \%$ al CPI (Tabla $\mathrm{N}^{\circ} 7$ ).

TABLA N ${ }^{\circ}$ 7: $\quad$ INDEXACIÓN PROMEDIO DE LA ENERGÍA LICITADA

\begin{tabular}{lcc}
\hline & \multicolumn{2}{c}{ Indexación promedio de los contratos } \\
\cline { 2 - 3 } Año & $2010-2011$ & 2012 en adelante \\
\hline CPI & $47 \%$ & $75 \%$ \\
Carbón & $15 \%$ & $15 \%$ \\
GNL & $7 \%$ & $7 \%$ \\
Diésel & $2 \%$ & $2 \%$ \\
CMg & $28 \%$ & $0 \%$ \\
\hline
\end{tabular}

Finalmente, se destaca el hecho que el precio promedio de todos los contratos licitados, indexado a diciembre de 2010, es de 82,15 US/ MWh. Si se resta de la evaluación el resultado de las licitaciones 3 y 3.1, el precio promedio de los contratos es de 65,61 US\$/MWh. En este contexto, es conveniente plantear la interrogante de cuál habría sido

${ }^{10}$ CGE licitó $2.150 \mathrm{GWh} /$ año, cuyo inicio de suministro era el año 2010, realizando una subasta de 27 bloques de igual tamaño (energía base). En conjunto dichos bloques debían comprometer una capacidad de suministro de $2.700 \mathrm{GWh}$ /año a partir del año 2013. Adicionalmente, cada uno de los bloques licitados comprometía un suministro variable por una suma correspondiente al $10 \%$ de la energía base definida en cada bloque. 
el resultado de las dos últimas licitaciones si el inicio de suministro se hubiera retrasado hasta el 2012, manteniendo la compra de las distribuidoras a costo marginal durante el 2010 y 2011.

\section{Lecciones aprendidas y elementos perfectibles}

El cambio regulatorio introducido en Chile el 2005 buscaba lograr un suministro eléctrico confiable a un precio competitivo y estable para incentivar el desarrollo de futuras centrales. El concepto que se formuló para dar cumplimiento a esta necesidad fue un proceso de licitaciones de suministro reguladas, lideradas por las empresas distribuidoras.

Durante el proceso de licitación, las principales variables que se operan son: cantidad de energía a licitar y periodo del contrato. En el contexto de las licitaciones de suministro, de acuerdo a la regulación vigente, es posible identificar tres stakeholders directos, cada uno de ellos con distintas necesidades y objetivos:

1. Empresa distribuidora: Cumplir con el Artículo 131 del DFL 4. Garantizar suministro a clientes regulados mediante existencia de contratos por próximos tres años. Realizar licitaciones públicas y abiertas. Adjudicar el contrato a quien oferte el menor precio.

2. Generador: Maximizar beneficio a accionistas mediante el desarrollo y operación de proyectos de generación que suministren energía a sus clientes, cumpliendo normativa vigente en el país. Política comercial acorde al riesgo que definan accionistas.

3. CNE y SEC: Supervisar que las licitaciones se realicen de acuerdo a la regulación vigente.

Si bien la regulación vigente entrega la atribución a las empresas distribuidoras de liderar este proceso, éstas no parecieran en teoría ser los agentes más indicados para ello. Las empresas distribuidoras no tienen incentivos concretos en la eficiencia del proceso, fundamentalmente tienen la presión de dar cumplimiento a la obligación de contratación establecida en el Artículo 131 de la ley.

No se debe confundir el objetivo fundamental de las licitaciones con una obligación establecida en el Artículo 131 de la ley eléctrica, que administrativamente obliga a las empresas distribuidoras a tener contratos que permitan abastecer la totalidad del consumo proyectado 
a lo menos por los próximos tres años. En este contexto, la dinámica de materialización de inversiones en generación, en conjunto con ciertas coyunturas en el mercado eléctrico, pueden determinar la dinámica de precios de largo plazo.

En el caso particular de las licitaciones que se realizaron en el país, la opción de desarrollar contratos puentes, de corto plazo, podría haber sido una alternativa interesante de haber explorado para sortear el periodo de estrechez energética. Paralelamente, se podría haber realizado una licitación para comprometer el suministro de largo plazo en un periodo ajeno a la coyuntura. Es importante destacar que la legislación vigente no exige a las empresas distribuidoras tener contratos de largo plazo, independiente de que sus accionistas estén interesados en ellos para reducir los riesgos del negocio.

En la sección 4 se mostró que cada generador, para un parque dado, tiene un nivel de generación conveniente de contratar. La decisión comercial de situarse en otro nivel de contratación inmediatamente involucra la necesidad de establecer contratos de precios más elevados. Como se mencionó anteriormente, este aspecto naturalmente resta competitividad a un esquema de licitaciones donde los generadores que participan ya tienen comprometida parte relevante de capacidad de contratación eficiente, a no ser que exista la posibilidad de ofertar energía mediante el desarrollo de un nuevo proyecto. Sin embargo, para ello se requiere realizar la licitación con una anticipación suficiente como para que el proyecto pueda ser desarrollado antes del inicio del contrato que se está licitando.

Respecto a la arquitectura de los bloques a licitar, es relevante tener en consideración dos aspectos. Primero, su definición debe ser revisada. El mercado eléctrico tiene características que lo diferencian de la comercialización de otros commodities. Fluctuaciones de demanda, escasa capacidad de almacenamiento, costos de inversión y operación, y restricciones técnicas de operación, generan nichos donde distintas tecnologías desarrollan ventajas competitivas: aquellas de generación base, media y punta. La definición de los bloques de demanda a licitar debería tener en consideración dicha definición para aprovechar las ventajas competitivas de cada uno de los actores. Sin embargo, éste es un aspecto que aún está en estudio, y conjuntamente ha generado preocupación en licitaciones realizadas en otros mercados (Castro et al., 2008). 
Por otra parte, está la incertidumbre en la variabilidad y crecimiento de la demanda, que puede ser traspasada al generador o ser administrada por la empresa distribuidora mediante la definición de distintos tipos de contratos; para ello es relevante reflejar de mejor forma las características de la demanda en la definición de bloques a licitar. Por ejemplo, se pueden definir contratos tipo take or pay y contratos de consumo variable.

En relación con las indexaciones de los contratos, la composición de la fórmula de indexación es un aspecto que debe ser revisado para valorizar adecuadamente aquellos riesgos que se están traspasando a clientes y aquellos riesgos que están siendo asumidos por empresas generadoras.

Finalmente, se recomienda revisar aspectos tales como: 1) aumentar el nivel de involucramiento del regulador en la definición de las licitaciones, 2) estandarizar los tipos de contratos, 3) mejorar la calendarización del proceso de modo de definir las ventanas de oportunidad en el mercado, 4) separar licitaciones para nueva capacidad y capacidad existente, 5) conceptualizar medidas recíprocas para mitigar y/o compartir riesgos.

\section{Conclusiones}

Las licitaciones de suministro en Chile se desarrollaron como un mecanismo para impulsar inversiones en el sector, mediante la definición de un esquema de precio de mercado y estable en el largo plazo. Además, sirvieron para resolver una situación administrativa-contractual de las empresas distribuidoras.

Entre los años 2006 y 2009 se realizaron tres grupos de licitaciones. Debido a una situación coyuntural del mercado eléctrico, el regulador reiterativamente aumentó el precio máximo aceptable en las ofertas. Particularmente en la licitación del 2009 el precio de largo plazo máximo a ofertar fue mayor que el costo de desarrollo de tecnologías hidráulicas o térmicas a carbón, que se esperaba se desarrollarían en el largo plazo en el sistema (el Decreto Supremo Nº130/2008 estableció un precio máximo de 125,164 US\$/MWh).

El precio promedio de las licitaciones a diciembre de 2010 fue 82,1 US\$/MWh. Si bien este precio parece estar alineado con la perspectiva de costo de desarrollo de una central genérica a carbón, no hay 
que desconocer que el promedio esconde imperfecciones que es importante destacar:

1. Existe una alta dispersión en el precio de los contratos de las distintas distribuidoras, y una diferencia importante entre el precio de contratos licitados en distintos periodos de tiempo. En algunos casos, recogiendo el precio de escasez de corto plazo, se asigna un precio de largo plazo elevado a bloques de energía que serán suministrados en base por un periodo de 14 años.

2. Existe una alta dispersión en la estrategia de indexación. Si bien es cierto que la fórmula de indexación es un instrumento utilizado por los generadores para cubrir el riesgo, de acuerdo a lo analizado, la composición de este índice debe ser evaluada al momento de adjudicar los contratos. Adicionalmente, a nivel promedio existe una diferencia estructural entre la indexación utilizada por los generadores en las primeras licitaciones y la indexación que se tendrá a partir del 2012. Esta última tiene una composición $75 \% \mathrm{CPI}$.

Dada la situación coyuntural del mercado, el contexto administrativo definido en las licitaciones, y las políticas comerciales de las empresas generadoras, la opción más razonable para éstas era abstenerse de presentar ofertas y esperar que subiera el precio máximo de oferta. Se destaca la poca flexibilidad de los contratos, en términos de compartir el riesgo y reconocimiento de un periodo coyuntural donde la estrechez del mercado indudablemente hacía poco atractiva la contratación en el corto plazo.

En las primeras licitaciones el margen comercial esperado de la industria fue menor, y la indexación más ajustada según las características de la fuente primaria de energía de cada empresa generadora; esto debido a que los generadores se encontraban en una condición inicial de vencimiento de un bloque importante de contratos $y$, probablemente, a un menor nivel de conocimiento del mecanismo de licitación. A medida que los generadores se comienzan a contratar, sin comprometer nueva capacidad de generación sustancial en el mercado ${ }^{11}$, naturalmente las licitaciones comienzan a despejar precios más elevados debido al balance de riesgo de los generadores. Este último concepto es relevante al definir un esquema de licitaciones en un mercado hidrotérmico, donde

11 Sólo Guacolda comprometió nuevas inversiones explícitamente en los contratos. 
la oferta disponible sufre variaciones intrínsecas año a año. En este contexto, si bien la correcta definición de diversas variables de diseño de las licitaciones es relevante, como por ejemplo el tamaño de los bloques y la asignación de demanda base o variable, previamente hay que evaluar aspectos tales como: si realmente existe un nivel apropiado de competencia entre los agentes existentes; si dichos agentes tienen la posibilidad de desarrollar nuevas plantas dentro del calendario definido para el bloque de energía que se está licitando, y si las barreras de entrada al proceso de licitación son bajas para nuevos agentes.

A su vez, al momento de diseñar una licitación, la empresa distribuidora y el regulador deben tener conciencia que la capacidad competitiva no es sólo el margen de capacidad en el sistema, sino que está ligada directamente con la capacidad comercial de generadores para aumentar su nivel de contratación sin aumentar significativamente su exposición al mercado spot.

En este trabajo se ilustró que cada empresa generadora, para un parque dado, tiene un nivel de contratación óptimo. La decisión comercial de situarse en otro nivel de contratación inmediatamente involucraría la necesidad de establecer contratos con precios más elevados. Como se mencionó anteriormente, este aspecto naturalmente resta competitividad a un esquema de licitaciones a no ser que exista la posibilidad de ofertar con un nuevo proyecto y/o existan bajas barreras de entrada para terceros. Sin embargo, cada vez que se desea incorporar nueva capacidad al sistema se requiere realizar la licitación con una anticipación suficiente como para que el proyecto pueda ser desarrollado antes del inicio del contrato que se está licitando. Cabe destacar que al final de los procesos de licitación informados, no se logró la incorporación significativa de nuevos actores en el mercado. Si bien hay cuatro nuevas empresas que se adjudicaron contratos, dos de ellas tienen generación gas-diésel, que en el largo plazo no aportarían generación base en el sistema. Otra de las empresas es Monte Redondo, correspondiendo a un parque eólico, filial del grupo GDF Suez. En términos de precio promedio de energía por generador, estas cuatro empresas presentan los precios más altos.

Si bien existe un límite legal de tres años que gatilla los procesos de licitaciones para renovación de contrato, la función del regulador debiera ser, entre otras cosas, incentivar a la empresa distribuidora para anticiparse al mercado para así obtener precios más competitivos, esto 
especialmente en situaciones donde no hay incertidumbre importante acerca de los volúmenes a licitar por la empresa distribuidora (e.g. bloque de suministro base).

El regulador debería identificar claramente los riesgos de mercado que se podrían asignar a clientes y aquellos riesgos que deberán ser asumidos por las empresas. Dada la incertidumbre en las condiciones de mercado de contratos de largo plazo es importante definir políticas que permitan mitigar y/o compartir dichos riesgos de manera recíproca.

Por último, es fundamental que el regulador tome una posición más activa en el proceso, introduciendo herramientas que permitan aumentar los grados de flexibilidad para enfrentar las incertidumbres futuras. Es central que defina criterios que permitan identificar los niveles de competencia y que tome acciones correctivas cuando identifique que no se logra la competencia. Los modelos de Brasil y Colombia se constituyen como buenas referencias para tomar en cuenta en estas dos dimensiones, considerando también que es difícil aplicar reglas comunes en diferentes países.

\section{REFERENCIAS}

Castro, L. de, M. Negrete-Pincetic y G. Gross. "Product Definition for Future Electricity Supply Auctions: The 2006 Illinois Experience". The Electricity Journal, 21(7): 50-62, 2008.

Moreno, R., L. A. Barroso, H. Rudnick, S. Mocarquer y B. Bezerra. "Auction Approaches of Long-Term Contracts to Ensure Generation Investment in Electricity Markets: Lessons from the Brazilian and Chilean Experiences". Energy Policy, 38(10): 5758-5769, 2010.

Roubik, E. y H. Rudnick. "Assessment of Generators Strategic Behavior in Long Term Supply Contract Auctions Using Portfolio Concepts". IEEE Powertech 2009 Conference, Búcarest, Rumania, Jun 28-Jul 2, 2009.

Rudnick, H. y S. Mocarquer. "Contract Auctions to Assure Supply Adequacy in an Uncertain Energy Environment". IEEE Power Engineering Society General Meeting, Montreal, Canadá, Jun 18-22, 2006. 